\title{
Characterization of Portuguese Historical Gypsum Mortars: a Comparison between Two Case Studies
}

\author{
T.Freire ${ }^{1, a}$, A.Santos Silva ${ }^{1, b}$, M. R. Veiga ${ }^{1, c}$ and J. de Brito ${ }^{2, d}$ \\ ${ }^{1}$ Laboratório Nacional de Engenharia Civil, I.P., Av. do Brasil 101, 1700-066 Lisbon, Portugal \\ ${ }^{2}$ Instituto Superior Técnico, Av. Rovisco Pais, 1049-001 Lisbon, Portugal \\ amtfreire@gmail.com, bssilva@Inec.pt, 'rveiga@Inec.pt, djb@civil.ist.utl.pt
}

Keywords: Characterization, chemical and physical properties, historic gypsum plasters

\begin{abstract}
The use of gypsum plaster for interior covering of walls and ceilings in the Portuguese architecture was particularly expressive in the period between the XVIII and the XX century. However, information about this important heritage is almost inexistent, which is leading to a fast loss of important patrimony.

In this paper, the results of the characterization of gypsum plaster samples belonging to two buildings from the same historical period (end of the XIX century and beginning of the XX), situated in distant geographical regions of Portugal are presented and discussed.

XRD, TGA-DTA, optical microscopy and SEM-EDS observations were used for the chemical and microstructural characterization. Some physical and mechanical properties, such as capillary absorption, dynamic elasticity modulus and compressive strength were also determined and a relationship between the characteristics observed in the samples and the technology associated to their use and application on site, as well as the possible existence of regional influences on all these aspects, are discussed.
\end{abstract}

